\title{
SOME EPIDEMIOLOGICAL ASPECTS OF SUBFERTILE WOMEN WHO UNDERWENT LAPAROSCOPY
}

\author{
Far/ana Deeba ${ }^{1}$, ABM. Muksudul Alam² ${ }^{2}$ Nilufar Nasrin Ava ${ }^{3}$ \\ Md. Rafiqul Islam ${ }^{4}$. Abdul Matin ${ }^{5}$. Rita Khan ${ }^{6}$
}

\begin{abstract}
Objective: Epidemiological aspects of sitbfertile women underwent laparoscopy. Place of Study: This retrospective study was done in the Obstetrics and Gynaecology Department of Bangladesh Medical College hospital.
\end{abstract}

Duration: July 2003 to June 2004.

Study Population: Women suffering from primarv and secondary subfertility, who had under gone laparoscopy. Total 61 patient had laparoscopy for evaluation of subfertility. No documents were available for 6 patient and they were excluded from the study.

\begin{abstract}
Result: The study group comprises 55 cases of which $67.37 \%$ was of primary and 32. 73",, was of secondary subfertility. Professional women group (56.4\%) was higher than housewife group (43.6\%). In this study $11.11 \%$ had history of spontaneous abortion and 33.33\% had history of MR. In this study menstrual period was within 7 days in $70.9 \%$ cases and in $10.9 \%$ cases were more than 7 days, in $14.54 \%$ cases menstrual cycle was more than 35 days and in $3.64 \%$ cases were less than 22 days. $40 \%$ of the patient did not used any contraceptive
\end{abstract}

Conclusion: The number of subfertility visits' has increased in the last few rears because of increasing awareness for available services and option for resolving subfertilitv. Prompt investigation and appropriate referral allow a couple to receive advice and treatment to help them reach their goal

\section{Introduction}

Sub fertility is defined as the inability of a couple to achieve conception after one year of unprotected coitus ${ }^{1}$. Approximately $90 \%$ of couples with unprotected intercourse will conceive within 1 year $^{2}$. Primary sterility is an absolute state of inability to conceive whereas secondary sterility is the same state developing after an initial phase of fertility ${ }^{3}$. Childlessness may be a tragedy to the married woman, and can be a cause of marital upset as well as of personal unhappiness and ill health. The prevalence of sub fertility ranges from $7-28 \%$ depending on the age of the womanS. A primmary diagnosis of a male factor is made about $30 \%$ of infertile couples . An abnormality in the woman is responsible for remaining $40-60 \%$ of cases ${ }^{2}$.

1. Dr. Karzana Deeba, MBBS.FCPS. Medical Officer. Nayatola G.O.D Dhaka. Bangladesh.

2. Dr. ABM. Muksudul Alam. FCPS. MD. Principal Shahid Shurawardy Medical College and Hospital, Dhaka.

3. Dr. Nilufar Nasrin Ava, FCPS. Junior Consultant of Obstetrics \& Gynaecology, Dhaka Medical College and Hospital.

4. Dr. Md. Rafiqul Islam, DCH. M.Phil(Int.Health). Assistant Professor. Pediatrics. Shahid Shurawardy Medical College and Hospital,Dhaka.

5. Dr. Abdul Matin MBBS.MD. Assistant Professor. Pediatrics. Shahid Shurawardy Medical College and Hospital, Dhaka.

6.Dr. Rita Khan. MBBS, M.P.H. M.O. NICR\&H Mohakhali. Dhaka.
Correspondence:

Dr. Far/ana Deeba

Nayatola G.O.D Dhaka. Bangladesh.

About $15 \%$ of normal fertile couples require more than 1 year to conceive and some of the "unexplained" causes of subfertility may simply be a part of this normal $15 \%{ }^{4}$. The success rates of treatment for subfertility depend on a variety of factors including cause of subfertility, womans age, duration of subfertility and availibilities of modern facilities of investigation and treatment ${ }^{5}$. The number of subfertility visits has increased in the last few decades. The reasons for the increase in attention given subfertility are multiple. Couples are less willing to simply accept childlessness and are increasingly aware of the available services and options for resolving subfertility. Increasing awareness of the psychological consequence of the problem led to increasing level of sophistication in evaluation and treatment of subfertility. When an anticipated conception fails to occur in a timely fashion and a couple begins to consider subfertility as a diagnosis their reactions can be intense and terrifying. Self-images are threatened, sexuality can be affected, and feelings of adequacy may be destroyed; feeling of loss of control, anger, guilt, shame, and resentment can alter behaviour and become contributing factors, to turn a relationship into negative consequences As an individual or couple actually confronts subfertility they may progress through stages. including denial, anger, grief, and resolution. A recognition of these stages may assist the practitionar in providing appropriate support and counselling. Treatment cycles often begin with high hopes and expectations and end with disappointment. 
Laparoscopy is a transperitoneal endoscopic technique that provides excellent visualization of the pelvic structures and permits the diagnosis and some times treatment of gynaecological disorders. It detects some pathology in otherwise tested normal woman, tubal morphology and patency by dye testing, ovulation by direct viewing corpus lutium during secretory phase of cycle, pre-operative selection for tuboplasty operations, post-tuboplasty follow up, other pelvic diseases $^{6,7}$. Investigation of subfertility is not completed without laparoscopy. In our country use of laparoscopy is limited to a few teaching hospitals. Philip Bozzini, in 1805 attempted to observe the interior of the urethra with a simple tube and candle light ${ }^{8}$. In 1877 Nitze added a lens system. Edison in 1880 the added incandescent lamp to the endoscope. Thus the use of multiple telescope lenses were possible $^{9}$. In 1901, professor Georg Kelling reported his examination of the stomach and esophagus ${ }^{10}$.

\section{Material and Methods}

This retrospective study was done in the Obstetrics and Gynaecology department of Bangladesh Medical College hospital during the period from July 2003 to June 2004. Women suffering from primary and secondary subfertility, who had laparoscopy after giving written consent, during the period from July 2003 to June 2004 with normospermic husband were included in this study. During this one year period, there were total 61 patient had laparoscopy for evaluation of subfertility. No documents were available for 6 patient and they were excluded from the study. Women with a)Haemodynamic instability or coagulopathy b) Chronic obstructive airway disease c) Known massive intra-abdominal adhesion, d) Suspected malignancy were excluded from the study.

Consent was taken from the department and hospital authourity for analysising available documents related to laparoscopy. Data was collected in a pretested semi structured questionnarie from patient history sheet and operation theater notes.Data was analyzed by using Micro-Soft Excel statistical programe.

\section{Results}

The study group comprises 55 cases of subfertile woman in which 37 patient (67.37\%) of Primary subfertility and 18 patient (32.73\%) were of Secondary subfertility (Table I) Primary and Secondary subfertility were high in the 26-30 years age group but in the 20-25 years age group primary subfertility were high. (Table II) Among the studied women, 24 (43.6) patients were house
Table-I

Types of Subfertility (N-55)

\begin{tabular}{|l|l|l|}
\hline Types Subfertility & No. of Patient & Percentage \\
\hline Primary Subfertility & 37 & 67.37 \\
\hline Secondary Subfertility & 18 & 32.73 \\
\hline
\end{tabular}

Table- II: Incidence according to age distribution (N-55)

\begin{tabular}{|l|l|l|l|l}
\hline Age & $\begin{array}{l}\text { Cases in } \\
\text { primary } \\
\text { subfertility }\end{array}$ & Percentage & $\begin{array}{l}\text { Cases in } \\
\text { secondary } \\
\text { subfertility }\end{array}$ & Percentage(\%)i \\
\hline $20-25$ & 13 & 25.45 & 1 & 1.82 \\
\hline $26-30$ & 16 & 29.09 & 14 & 25.45 \\
\hline $31-35$ & 7 & 12.73 & 2 & 3.64 \\
\hline $36-40$ & 1 & 1.82 & 0 & 0 \\
\hline
\end{tabular}

Table-III :Profession (N-55)

\begin{tabular}{|l|l|l|}
\hline Occupation & No. of cases & Percentage (\%) \\
\hline House wife & 24 & 43.6 \\
\hline $\begin{array}{l}\text { Professional } \\
\text { personnel }\end{array}$ & 31 & 56.4 \\
\hline
\end{tabular}

Table- IV: Obstetric History (N-33)

(Incase of secondary subfertility)

\begin{tabular}{|l|l|l}
\hline Obstetrics History & No of Patient & Percentage (\%) \\
\hline Still birth & 1 & 5.56 \\
\hline Spontaneous abortion & 2 & 11.11 \\
\hline MR & 6 & 33.33 \\
\hline Ectopic pregnancy & 1 & 5.56 \\
\hline Vaginal delivary & 5 & 27.78 \\
\hline LUCS & 3 & 16.67 \\
\hline
\end{tabular}

Table-V: Menstrual History (N-55)

\begin{tabular}{|l|l|l|}
\hline (1) Menstrual period & No. of cases & $\begin{array}{l}\text { Percenta } \\
\text { ge (\%) }\end{array}$ \\
\hline Within 4-7 days & 39 & 70.9 \\
\hline More than 7 days & 6 & 10.9 \\
\hline Less than 4 days & 10 & 18.2 \\
\hline (2) Menstrual cycle & & \\
\hline 22 -35 days & 45 & 81.81 \\
\hline More than 35 days & 8 & 14.54 \\
\hline Less than 22 days & 2 & 3.65 \\
\hline (3) Amount of bleeding & & 80 \\
\hline Normal & 44 & 11 \\
\hline Excessive & 6 & 9 \\
\hline Scanty & 5 & \\
\hline
\end{tabular}




\begin{tabular}{|l|l|l}
\hline (4) Other complain & & \\
\hline Menorrhagia & 4 & 7.27 \\
\hline Polymenorrhoea & 1 & 1.82 \\
\hline Amenorrhoea & 2 & 3.65 \\
\hline Dysmenorrhoea & 11 & 20 \\
\hline Metrorrhagia & 1 & 1.82 \\
\hline Inter Menstrual bleeding & 1 & 1.82 \\
\hline (5) No complain & 35 & 63.63 \\
\hline
\end{tabular}

Table- VI Past Contraceptive History (N-55)

\begin{tabular}{|l|l|l|}
\hline Contraceptive method & No. of cases & Percentage \\
\hline No method wsed & 22 & 40.00 \\
\hline IUCD & 4 & 7.27 \\
\hline Oral Pill & 13 & 23.64 \\
\hline Barrier Method & 16 & 29.09 \\
\hline Total & 55 & 100.00 \\
\hline
\end{tabular}

wife, 31 (56.4) patient were service holder they were teacher, medical personnel, other technical personnel, lawyer and other professional personnel (Table III). Secondary subfertility had history of 5.56\% still birth, 11.11\% had spontaneous abortion, 33.33\% had M. R., $5.56 \%$ had Ectopic pregnancy, $27.78 \%$ had vaginal delivery, 16,67\% had L.U.C.S (Table IV). In this study menstrual period was within 7 days $70.9 \%$ and more than 7 days was $10.9 \%$. Menstrual cycle 22-35 days in $81.81 \%$ more than 35 days in $14.54 \%$ less than 22 days in $3.64 \%$. In this study $7.27 \%$ patient complains of menorrhagia, $\quad 1.82 \%$ polymenorrhoea, $3.64 \%$ amenorrhoea, $20 \%$ dysmenorrhoea, $1.82 \%$ metrorrhagia, $1.82 \%$ inter menstrual bleeding and $63.63 \%$ patient having no complain. In this study normal amount of bleeding was $80 \%$, excessive in amount $11 \%$ and scanty $9 \%$ cases. (Table V) Table VI shows that $40 \%$ of the patient did not used any contraceptive other $60 \%$ used contaceptive among them barrier method was more frequent.

\section{Discussion}

A laparoscopy and dye ("lap and dye") test is the most reliable, albeit expensive, tool used to diagnose sub fertility. Morphological abnormalities of the fallopian tubes can be seen directly, and the general pelvic appearance may give some clue to likely cause of any abnormalities and laparoscopic treatment of early endometriosis improved fertility prospects by $13 \%$ over the next nine months 11 In this study, there were more cases of primary subfertility (67.3\%) and than the secondary subfertility ( $32.7 \%$ ). This was due to the fact that people are now becoming conscious and they come for treatment earlier.

More primary subfertility (25.45\%) cases were coming for treatment in the 20-25 years age group than secondary subfertility (<2\%) cases. But in the 26-30 years age group treatment seeking behavior was almost equal between the primary subfertility (29\%) group and secondary subfertility ( $25.45 \%$ ) group. An inverse relationship exists between fecundability and the age of the woman. The decline in fecundability begins in the early thirties and progresses rapidly in the late thirties and early forties. Couple in some cases have voluntarily delayed childbearing in favour of establishing careear and may experience an age-related decline in fertility. Among the treatment seekers professional women group (56.4\%) was higher than housewife group (43.6\%). Probably this was due to financial solvency, decision making capacity, more information availability, more awareness. This was because, working women had age related dicline in fertility and more woman from this group came to visit gynaecologists. Past obstetric history is important in cases of secondary subfertility. MR. Abortion, Puerpeal sepsis, may causes tubal damage after pelvic infection. In this study $11.11 \%$ had history of spontaneous abortion and $33.33 \%$ had history of MR. In some cases the choice of prior contraceptive method may have contributed to subfertility. as with the use of some intrauterine devices (IUDs). Oral pill may cause post-pill amenorrhoea by suppressing the hypothalamo-pituitary axis. Aetiology of subfertility varies between countries and even regions and a knowledge of local disease pattern is essential, if appropriate investigations are to be performed. Regular menstrual cycle usualy indicates regular ovulation which is a basic needs for achiving fertility. Generaly failure to ovulate is associated Ivih ammenorrhoea. But regular anovulation in menstrating woman can occur - may be a feature of hypothalamic anovulation, hyperprolactemia due to drugs, pituitary adenoma or primary hypothyroidism. Polycystic ovaries. subclinical adranal failure and diabetes mcllitus, lutinized unruptured follicles and luteal phase deficiency. In this study menstrual period was within 7 days in $70.9 \%$ cases and in $10.9 \%$ cases more than 7 days, in $14.54 \%$ cases menstrual cycle was more than 35 days and in $3.64 \%$ cases less than 22 days.

The problem should be investigated first by review of historical factors, including the onset of menarche; present cycle length (intermenstrual interval); and presence or absence of premenstrual symptoms (molimina), such as breast tenderness, bloating or dysmenorrhea. Signs and symptoms of systemic disease, particularly of hyperthyroidism or hypothyroidism, and physical signs of endocrine disease (eg, hirsutism. galactorrhea. and obesity) should be noted. The degree and intensity of exercise, a history of weight loss, and complaints of hot flushes all are clinical clues to possible endocrine or ovulatory dysfunction.

\section{Conclusion}

The number of subfertility visits has increased in the last 
Prompt investigation and appropriate referral allow a couple to receive advice and treatment to help them reach their goal of a pregnancy more quickly, and may alleviate some of the distress associated with subfertility. Doctors in primary care can have an invaluable role in starting this process and providing support during further investigation and treatment.

Investigations should follow a systematic protocol designed to identify:

- Tubal or uterine abnormalities

- Anovulation

- Impaired spermatogenesis.

\section{References}

l.Jefcoate, Sir Norman: Jefcoats Principles of Gynaecology. Sixth edition, Butter Worth and Co. ltd. London 2001: 3052

2.De Cheney AH, Nathan L. Current Obstetric \& gynecologic Diagtnosis \& treatment. 9th edition, McGrawHil Companies, New York, 2003:980

3.Taylor A: ABC of subfertility- making a diagnosis. British Medical Journal, Vol.327 August 2003, pp 494-97.

4. Hart R: ABC of subfertility- unexplained subfertility, endometriosis and fibrosis. British Medical Journal, Vol.327 September 2003, pp 721-24.

5. Hull MGR, Cagill DJ: Female subfertility. Endocrinol metabol Clin, North Am 1998;27:851

6. Hsu S, Mitwally MF, Aly A. et al: Laparoscopic ovarian biopsy and subfertility. Srp Arh Celok Lek. 2003 Sep-Oct;
Sturgis SH (eds): Progress in Gynecology.Vol 3. New York. Grune \& Stratton, 1957. pp 191-208.

8. John Howkins,Christopher N.Hudson. Shaw's Text Book of Operative Gynocology. 5th edition. Churchill Livingstone Pvt.Ltd.New Delhi2000:40-449.Philips J.M Corsos.S L Keith L.Levenson.K.J.and YuzpeA.A.(Eds) Laparoscopy.Baltimore, Williams and Wilkins,1997.

10.Kelling G: Uber Oesophagoskopie,Gastrokopie und Koelioskopie. Munce Med Wochenschr 49:21-24,192.

11. Marcoux S, Maheux R, Berube S. Canadian Collaborative Group on Endometriosis. Laparoscopic surgery in infertile women with minimal or mild endometriosis. N Engl J Med 1997;337:217-22. 